\title{
El sufrimiento como valor: expertise y compromiso en las reparaciones económicas a las víctimas de una "tragedia" argentina
}

\author{
Suffering as a Value: Expertise and Commitment in the Economic \\ Reparations to the Victims of an Argentinean "Tragedy"
}

\author{
Diego Zenobi ${ }^{*}$ \\ Universidad de Buenos Aires \\ Consejo Nacional de Investigaciones Científicas y Técnicas (Conicet), Argentina
}

D0I: $10.22380 / 2539472 X .1312$

\begin{abstract}
RESUMEN
En las últimas décadas puede observarse la proliferación de mecanismos de reparación de la violencia que clasifican, jerarquizan y modelan la condición de víctima. Aquí me baso en la idea de que existe una relación entre la finalidad de esos dispositivos y las expectativas de las personas que realizan sus propias evaluaciones morales sobre aquellos. En este trabajo analizo los pedidos de indemnización elaborados por los abogados de las víctimas del incendio de la discoteca Cromañón, que ocurrió en 2004 y dejó 194 muertos y 1.500 heridos. Mostraré que la elaboración de aquellas demandas está estrechamente conectada con las expectativas de justicia sostenidas por estos expertos del derecho comprometidos con la lucha pública y política de las víctimas. Pretendo mostrar que así como los dispositivos hacen personas, también las personas hacen dispositivos.
\end{abstract}

Palabras clave: reparaciones, víctimas, expertos, Argentina, tragedia de Cromañón.

\section{ABSTRACT}

In recent decades, a proliferation of mechanisms for the redress of violence can be observed. They classify and model the condition of the victims. Here I state that there is a relationship between the purpose of these mechanisms and the expectations of the victims' lawyers who make their own moral evaluations of them. In this paper I analyze the requests for compensation made by those lawyers of the victims of a fire occurred in Argentina that left 194 dead and 1500 injured. I will show that the elaboration of these requests is closely connected with the expectations of justice of those legal experts committed to their struggle. I will show that just as devices make people, so do people make devices.

Keywords: reparations, victims, experts, Argentina, tragedy of Cromañón. 


\section{Introducción: expertise y reparación del daño}

Desde fines del siglo XIX, las ideas sobre la responsabilidad estatal con relación a ciertos tipos de daños y su reparación han recorrido un largo camino. La idea según la cual el Estado debe reparar el daño por el cual es responsable se remonta al año 1873, cuando, en el marco del famoso caso Blanco, el Tribunal de Conflictos francés determinó que el Estado debía indemnizar a una niña que fue herida al ser atropellada por un vagón operado por trabajadores de una fábrica de gestión estatal (Jiménez 2013). Si bien desde inicios del siglo XX los pedidos reparatorios dirigidos a Estados involucrados en situaciones bélicas fueron recurrentes, la noción de reparación adquirió un sentido renovado luego de la Segunda Guerra Mundial. Las políticas reparatorias que se pusieron en marcha décadas después del Holocausto para indemnizar a diferentes grupos sociales que sufrieron la violencia en ese periodo se constituyeron en un estándar a la hora de poner en marcha formas de compensación por las injusticias cometidas por los Estados (Chaumont 2000; Torpey 2001). Con la invención y difusión de la justicia transicional (Lefranc 2009) como un modo específico de luchar contra la impunidad y promover la defensa de los derechos humanos, las políticas reparatorias alcanzaron difusión global.

Pero también existen otros contextos y tipos de casos en los que surgen demandas de reparación que no serían reconocidos a priori como "casos de derechos humanos" atendibles por la justicia transicional, esto es, que no están directamente conectados con la violencia ni el terror provenientes del Estado. Se trata de situaciones que involucran daño ambiental (Fourcade 2016) o sociocultural (Oliveira 2020), catástrofes naturales (Revet 2007) o tecnológicas (Petryna 2004; Silva 2015), contaminación de personas con agentes patógenos (Barbot y Dodier 2015; Fillion y Torny 2015), etc.

Con el paso de los años, se ha configurado un campo de expertise muy desarrollado en torno a la reparación, que incluye la existencia de publicaciones especializadas, posgrados, protocolos, entre otros. Algunas de las preguntas planteadas por filósofos del derecho, cientistas sociales y los propios agentes de justicia con el objetivo de diseñar mejores y más adecuadas modalidades reparatorias permiten entrever algunos conflictos y dilemas recurrentes que son objeto de reflexión: ¿cuándo podemos afirmar que ciertas formas de ejercer la violencia deben ser entendidas como violaciones a los derechos humanos?, ¿cuáles son los mecanismos a través de los cuales podemos demostrar el vínculo entre un hecho y el daño que se denuncia y por el cual se exige reparación?, ¿quién 
y cómo debe certificar el daño?, ¿cómo reparar aquello que se nos representa como irreparable?, ¿cómo estimar la valuación del daño cuando hablamos de sufrimiento y muerte? ${ }^{1}$.

En el presente trabajo abordaré algunos de esos interrogantes comunes a diversos contextos de violencia en los que se pone en juego la expectativa de reparación. Analizaré el papel que desempeñaron algunos abogados con relación a los dispositivos de reparación económica - concretamente, las solicitudes de indemnización - orientados a reparar los efectos destructivos de un incendio ocurrido en la ciudad de Buenos Aires en 2004, durante un concierto de rock en el establecimiento República Cromañón, que tuvo como saldo 194 jóvenes muertos y 1.500 heridos. Este hecho - que fue definido por la prensa nacional como la mayor catástrofe no natural de la historia argentina- provocó una profunda conmoción social y desató un proceso político contencioso de enorme magnitud que se extendió con mayor intensidad entre 2005 y 2008. Durante esos años, los parientes de los fallecidos y los sobrevivientes impulsaron movilizaciones colectivas mensuales que reunieron a miles de personas que exigían justicia en las calles de Buenos Aires: para ellos, justicia implicaba que el Estado fuera reconocido como responsable del incendio y que las personas acusadas judicialmente por lo sucedido fueran encarceladas. En ese movimiento de lucha llevé adelante mi trabajo de campo por dos años.

Paralelamente a esas acciones contenciosas en el espacio público, las víctimas también impulsaron acciones jurídicas en el ámbito penal y en el civil donde presentaron aproximadamente 1.600 solicitudes de indemnización ${ }^{2}$. La elaboración de una parte de esas demandas civiles presentadas por los abogados de los que aquí me ocupo estuvo alimentada por el lenguaje de los derechos humanos y por las herramientas desarrolladas en el marco de la justicia transicional. Esas acciones eran consideradas por las víctimas y por los abogados que las representaban como un paso más hacia el reconocimiento de la responsabilidad estatal por lo sucedido. En este trabajo mi punto de partida es que, aun cuando el papel anunciado de estos mecanismos reparatorios sea el de gestionar la situación de adecuada a las víctimas han dado diferentes respuestas a algunas de esas preguntas (Feldman 2000).

2 Entre 2008 y 2009 se desarrolló el juicio principal en el que se absolvió a la mayor parte de los acusados. Años después, esta situación fue modificada por instancias judiciales superiores que revirtieron el fallo, lo que condujo a prisión a más de una decena de personas, entre las que se encontraban el dueño del local, el gerente, los músicos de la banda de rock que tocaba esa noche y algunos policías y funcionarios estatales. Aún no han finalizado los juicios civiles, muchos de los cuales recibieron sentencias favorables para los demandantes y se continúan pagando. 
quienes han sufrido el daño y la violencia, aquellos deben tratarse como dispositivos conformados por un conjunto variable de agentes (quienes los conciben, quienes los ponen en funcionamiento y quienes son objeto de su intervención) y elementos (discursos, normas, objetos) que desempeñan distintos papeles y que se encuentran ensamblados (Dodier y Barbot 2017). De modos más bien sutiles y opacos - y mucho menos abordados por la literatura especializada en el tema-, esos dispositivos definen, clasifican y jerarquizan a las personas que han sufrido un daño y contribuyen a la producción social de su condición de víctimas (Zenobi y Marentes 2020).

Si observamos las cosas desde este punto de vista, se hace evidente que las víctimas no están solas, sino que son un producto social surgido de un complejo ensamblaje (Jensen y Ronsbo 2014). Este puede articular elementos tales como historias clínicas, test psicológicos, instrumentos de medición o aparatos de laboratorio, al igual que la participación de diversos tipos de especialistas como médicos, ingenieros, psicólogos, biólogos, abogados y expertos de varias disciplinas, quienes contribuyen a producir conexiones entre hechos y daños a través de los medios técnicos que manejan (Das 1995b; Dodier 2009; Todeschini 1999). En particular, en lo que respecta al derecho, las cuestiones que la normativa preocupada por reparar establece que deben encuadrarse, cuantificarse y demostrarse (tipos de daños, conexiones causales, etc.) son, en gran medida, sus propias creaciones (Ross Meyer 2014).

Como ya he anticipado, me ocuparé de los abogados comprometidos (Vecchioli 2006) con las víctimas y el movimiento político y mostraré cómo discuten los dispositivos de reparación económica disponibles y cómo trabajan por reformularlos, al menos en parte. Para abordar esta cuestión, central en este trabajo, me baso en las ideas de Dodier y Barbot (2017), quienes proponen una aproximación pragmática a los dispositivos frente a los cuales las personas se posicionan. La acción social puede verse modelada en la relación con estos, ya que los sujetos los critican o se apoyan en ellos para alcanzar sus fines (Dodier y Barbot 2017). Un enfoque procesual de esa relación coloca en el centro las evaluaciones morales que realizan los agentes, así como sus expectativas, más allá de las finalidades formales que los dispositivos puedan expresar. En este caso, veremos cómo los abogados que me ocupan — que son a la vez parientes de un joven fallecido y miembros del movimiento de lucha - alteran y reorientan los dispositivos indemnizatorios movilizando ideas, conceptos y herramientas provenientes de la justicia transicional, en la búsqueda de asimilar un caso desplegado en el ámbito del derecho civil a uno de derechos humanos.

Según Bourdieu (2000), el campo jurídico está estructurado en torno al efecto de desconocimiento que resulta de suponer que se basa en los principios 
de universalidad, neutralidad y autonomía en relación con las presiones externas. Lejos de ser un simple disfraz ideológico, se trata de la base del funcionamiento del campo. Aquí pretendo describir de qué modo aquella apropiación y manipulación “técnica” del dispositivo de reparación dejan expuesto un conjunto de consideraciones de tipo moral que lo modelan. Al hacerlo, mostraré que la manera en que se producen las demandas civiles está estrechamente conectada con las expectativas de conseguir justicia, sostenidas por los abogados comprometidos con la lucha de las víctimas a las que representan (Barbot, Winance y Parizot 2015). Mi intención entonces es evidenciar que, así como los dispositivos hacen personas, no es menos cierto que las personas hacen dispositivos.

\section{Los derechos humanos como recurso global/local}

Unos días después del incendio en Cromañón, desde el gobierno de la ciudad se pusieron en marcha medidas orientadas a atender la situación de las víctimas que, por cuestiones logísticas y coyunturales, quedaron a cargo de la Subsecretaría de Derechos Humanos de la Ciudad de Buenos Aires, sin que hubiera una intención de inscribir el caso dentro de ese universo ${ }^{3}$. Mientras eso ocurría, las personas movilizadas que exigían justicia - entre quienes estaban los abogados de los que aquí me ocupo- señalaban que el incendio había sido posible a causa de la corrupción política que toleraba el funcionamiento irregular de los locales nocturnos de la ciudad, los cuales operaban sin las condiciones mínimas de seguridad ${ }^{4}$. Los abogados a los que me refiero se presentan a sí mismos como víctimas, junto a otros familiares y a los sobrevivientes del hecho. Uno de ellos es el padre de un joven fallecido en el incendio y la otra mantuvo un vínculo de cercanía y afecto durante años con parte de su familia. Desde ese lugar, pusie-

3 Desde allí se puso en marcha un programa de atención a las víctimas que incluía asistencia médica (para la salud física y mental) y un subsidio mensual; en segundo término, en 2013 la legislatura de la ciudad sancionó una ley de reparación integral; en tercer lugar, el gobierno de la ciudad desplegó formas de reparación simbólica: día de conmemoración, intervenciones visuales en estaciones de metro, construcción estatal de un memorial y apoyo a uno construido por las víctimas.

4 Por este motivo, uno de los objetivos del movimiento entre 2005 y 2006 fue la destitución de Aníbal Ibarra, en ese entonces jefe de gobierno de la ciudad de Buenos Aires. Esto se logró en marzo de 2006, cuando fue sucedido por Mauricio Macri, quien ocho años después fue electo presidente de la república. 
ron en juego su expertise como parte de su compromiso con la causa política y la búsqueda de justicia impulsada desde el movimiento. Sobre un total de 1.600 pedidos indemnizatorios, elaboraron aproximadamente $160 \mathrm{y}$ se centraron en la responsabilidad estatal por la falta de controles adecuados. En las demandas que hicieron, la relación entre responsabilidad estatal y el daño sufrido fue trazada apelando a documentos, categorías y jurisprudencia aportados por el orden transnacional.

Si se considera el ámbito de lo transicional, estudios sobre Latinoamérica y Centroamérica han encontrado que, al inicio de las transiciones hacia la democracia, los esfuerzos jurídicos se centraron en el esclarecimiento de la verdad con un menor énfasis en la realización de juicios y el establecimiento de programas de reparación, cuestiones que se mantuvieron relegadas a un segundo plano (Gutiérrez 2019). Hacia la década de los noventa, esa tendencia se fue modificando. En el año 1997, luego de casi diez años de trabajo, la Organización de las Naciones Unidas (ONU) aprobó el documento La administración de la justicia y los derechos humanos de los detenidos: la cuestión de la impunidad de los autores de violaciones de los derechos humanos (civiles y políticos), que postula la necesidad de promover medidas de reparación integral, un modo de reparar que incluye diversas cuestiones como restitución, indemnización, rehabilitación y reparación simbólica.

Si observamos el caso argentino, desde mitad de los años noventa y sobre todo luego de los 2000, algunas de las demandas de los organismos de derechos humanos fueron incluidas como parte de las políticas estatales que incorporaban aquellas nociones de reparación promovidas por los organismos transnacionales (restitución, indemnización, rehabilitación y reparación simbólica) ${ }^{5}$. A lo largo de ese proceso, los damnificados por el terrorismo de Estado en Argentina fueron consagrados, legitimados y reconocidos como víctimas que debían ser reparadas (Guglielmucci 2015; Vecchioli 2005). En ese camino, el trabajo jurídico realizado por abogados comprometidos con la causa de los derechos humanos fue determinante. Vecchioli (2006) ha señalado que la posición de esos profesionales es construida desde dos frentes: se define por el compromiso público y colectivo con una causa y, al mismo tiempo, ese compromiso político se construye sobre la existencia de un conocimiento técnico, una expertise que los posiciona de un modo particular en el mundo del activismo y, sobre todo, en relación con las víctimas y sus familiares. En este sentido, ejercer la profesión se torna una condición de posibilidad del activismo jurídico. Los abogados que elaboraron las

5 Para un detalle sobre la evolución de las formas de reparación económica a estas víctimas, véase Guglielmucci (2015). 
demandas civiles que me ocupan también son abogados comprometidos, en este caso, con la lucha de las víctimas del incendio.

Como producto de la transnacionalización y la vernacularización, su globalización y las apropiaciones locales, los derechos humanos se han constituido en uno de los prismas centrales bajo el cual entender e interpretar diversos tipos de violencia (Merry 2006). Siguiendo este camino, aquellos profesionales del derecho plantearon la necesidad de una asimilación y solicitaron que el caso en cuestión fuera tratado siguiendo la doctrina de la Corte Interamericana de Derechos Humanos (Corte IDH) para casos de violaciones a los derechos humanos:

Somos los únicos abogados que hicimos el planteo de asimilación de la doctrina de la Corte IDH. Las otras demandas se estructuraron como demandas de daños tradicionales basadas en el derecho civil. Lo hicimos porque en la causa penal ya fueron probados los hechos de corrupción de parte de funcionarios del Estado que debían controlar las condiciones de seguridad del local para que no se incendie. Se violaron derechos humanos. (Abogada, entrevista, agosto de 2016)

Como parte de su trabajo para que el incendio del local República Cromañón fuera reconocido como un caso de derechos humanos en la justicia civil argentina, incorporaron a las demandas el documento de la ONU que lleva como título Principios y directrices básicos sobre el derecho de las víctimas de violaciones manifiestas de las normas internacionales de derechos humanos y de violaciones graves del derecho internacional humanitario a interponer recursos y obtener reparaciones (2005). Al citar el principio 8, señalan que "se entenderá por víctima a toda persona que haya sufrido daños [...] como consecuencia de acciones u omisiones que constituyan una violación manifiesta de las normas internacionales de derechos humanos o una violación grave del derecho internacional humanitario” (demanda civil presentada por un sobreviviente $)^{6}$. En esa misma línea, la jurisprudencia citada en las demandas refiere centralmente a casos tramitados por la Corte IDH de la Organización de Estados Americanos (OEA) y se centra en casos de violencia estatal y paraestatal en diferentes partes de Latinoamérica, como Argentina, Perú y Guatemala: desaparecidos, víctimas de violencia policial, personas torturadas, etc.

Se advierte en esta estrategia un intento de innovación que se presenta como una forma de lucha contra modos vigentes ya legitimados para situaciones que son entendidas a priori como de derechos humanos: esa jurisprudencia que refiere a hechos previos ya acreditados es reinterpretada en función de

6 Para respetar el anonimato de los involucrados y de los procesos, se omitirán otros datos de referencia de las demandas civiles citadas en el artículo. 
la propia lucha del presente. Los abogados son profesionales capaces de constituir en problemas jurídicos los problemas expresados en el lenguaje ordinario y tienen el poder de crear las aspiraciones jurídicas, de manipularlas - o de disuadirlas-, así como de anticipar las posibilidades de éxito de las diferentes estrategias (Bourdieu 2000, 190). Cualquier caso debe ser desingularizado para que sea visto como una demanda normal (Boltanski, Darré y Schiltz 1984) y las víctimas deben producir una definición del problema que denuncian más allá de su caso particular (Henry 2007). En ese camino, aquella expertise puede contribuir a promover una ampliación del propio caso tendiendo puentes y conexiones con otro tipo de situaciones. El paradigma de los derechos humanos aporta un lenguaje previsible y legítimo a las víctimas que aspiran a ser reconocidas, al asimilar el caso al de víctimas ya legitimadas en el contexto argentino como las del terrorismo de Estado.

\section{El sufrimiento (excepcional) como valor}

Acontecimientos que tienen orígenes muy diferentes, tales como desastres naturales, genocidios o situaciones de violencia política, pueden ser tratados como eventos críticos que alteran los marcos colectivos de percepción, transforman los órdenes sociales y subjetivos y propician nuevas formas de significación (Das 1995a). Se trata de situaciones que modifican las condiciones existentes, con lo cual generan nuevas posibilidades y producen y legitiman transformaciones de estatus y jerarquías (Visacovsky 2011). Ahora bien, ¿cómo es posible objetivar ese aspecto extraordinario, fuera de lo esperable, en un reclamo indemnizatorio?, ¿cuál es el sentido que ello adquiere cuando se trata de fundamentar la reparación de la violencia?

Si bien los artefactos estatales, como leyes, políticas públicas y normativa, hablaban del incendio como una tragedia y las víctimas lo llamaban masacre, ambas formas de nominación coincidían en destacar su aspecto singularmente negativo. Ese carácter excepcional del siniestro se vio reflejado en las demandas civiles. Tales artefactos jurídicos categorizaron al evento crítico como un hecho notorio y enfatizaron "lo indeleble de la tragedia que ha impreso en la sensibilidad de los ciudadanos, lo terrible de lo padecido, el descontrol y los daños que siguieron, como los sucesivos padecimientos de las víctimas" (demanda civil presentada por una sobreviviente). Así, desde la óptica de los abogados, el perjuicio que sufrieron las víctimas no estaba centrado solo en cuestiones patrimoniales 
o materiales, sino - y sobre todo- en su salud psíquica y emocional y en las consecuencias negativas que esto traía para la proyección de futuro de esos jóvenes, tal como se verá más adelante.

En la conformación de causas políticas a través de las cuales las víctimas reclaman y demandan derechos, es central la producción de una política de las causas (Barthe 2010) mediante la cual ellas pueden demostrar la relación entre un hecho del pasado y la situación de sufrimiento del presente. Se trata de las actividades orientadas a establecer lazos de causalidad entre hechos generadores y daños. Muchas veces, para comprender (el éxito o el fracaso de) una causa política, es necesario atender al proceso de construcción concomitante de la política de las causas. Las demandas de indemnización forman parte de la construcción jurídica de esas relaciones de causalidad ${ }^{7}$. Allí se destaca el papel de los expertos, sobre todo cuando estos se comprometen y apoyan la causa de las víctimas (Redfield 2006). Peritos técnicos de diversas profesiones que actúan en el ámbito judicial penal o civil ponen en juego técnicas morales (Gatti 2013) que contribuyen a producir normatividad, calificaciones y descalificaciones que tienen un estatuto de derecho (Lenoir 1993). Ellos pueden producir conexiones que contribuyen a que ciertos hechos sean socialmente definidos como tragedias, accidentes, masacres, etc.

En los artefactos jurídicos, como testimonios, resoluciones, leyes, decretos, normativas, etc., suelen incuirse términos que dan cuenta de la excepcionalidad de las situaciones sobre las que se legisla: en este caso, las categorías que se pusieron en marcha fueron magnitud, pánico, desesperación, letalidad y trauma. A través de cálculos, categorías técnicas y proyecciones, los arquitectos e ingenieros que actuaron como peritos señalaron que la estructura material y espacial del local impidió la correcta evacuación del público. En la demanda civil, ellos se refirieron a las condiciones materiales deficientes, "numerosísimas irregularidades estructurales en términos de estructura y ventilación, así como a [...] [las] muy numerosas y muy marcadas diferencias de dimensiones respecto a los medios de salida, entre los planos y la realidad" (demanda civil presentada por familiares de un fallecido).

En los informes forenses citados en las demandas se señala que algunos cuerpos exhibían "cianosis, negro de humo en rostro, laringe y tráquea y edema agudo pulmonar” (demanda presentada por la madre de un fallecido). El cianuro hallado por los forenses era una marca del carácter trágico de la situación,

7 La epistemología y la filosofía han participado de las discusiones sobre los usos jurídicos de nociones como causalidad o probabilidad en casos de demandas indemnizatorias por contaminación (Parascandola 1996). 
pues se trataba de un elemento letal que había reducido drásticamente las posibilidades de supervivencia. El cianuro actúa de manera extremadamente rápida por lo que, según los expertos, "con tres respiraciones en un ambiente en el que se encuentra condensada esa sustancia, la persona pierde el conocimiento, convulsiona y muere en minutos” (demanda civil presentada por un sobreviviente). Así, las condiciones materiales y subjetivas permitieron definir aquel escenario como una trampa mortal:

las posibilidades de escapar con vida de esa trampa mortal eran absolutamente inciertas y aleatorias [...]. [L]os médicos indicaron que [...] el efecto de la atmósfera lesiva, asimismo, pudo verse triplicado cuando la persona está en movimiento, lo que generalmente sucede frente al pánico y la desesperación. [...] Esos factores motivaron que las personas que estaban en el local se agolparan, empujaran y pisaran tratando de salir. Así se formaban verdaderas "pilas humanas" dentro del salón que llegaban hasta los 2 metros de altura. (Demanda civil presentada por un sobreviviente)

Si bien emociones negativas como el miedo, la desesperación y la angustia pueden representar dilemas morales para las víctimas que se movilizan políticamente (Zenobi 2020), en cambio, pueden traer buenos resultados en la arena legal (Bandes 1996). Aquí el sufrimiento extremo y excepcional aparece como un valor a pagarse.

Aunque el experto suele ser pensado como un agente que actúa en nombre de la ciencia y la técnica y que reclama para sí la neutralidad axiológica (Neiburg y Plotkin 2004), tal como ha advertido Boyer (2008), es la propia ideología de la expertise la que nos conduce a verlos de esa manera. De este modo, mientras que los expertos - abogados, en este caso- pueden sostener que las normas jurídicas son "neutrales”, desde una perspectiva analítica considero que las herramientas, explicaciones y normas técnicas que usan contribuyen a consagrar una cierta normatividad (Lenoir 1993). El saber médico realiza su aporte al dar cuenta del escenario temerario que debieron enfrentar los afectados por situaciones de desastres, en este caso particular, cuando - con base en una explicación que relacionaba la ansiedad, la transpiración y la respiración agitada- se definió que, a causa de aquella atmósfera lesiva, las posibilidades de morir se habían triplicado.

Como señala Ross Meyer (2014), la ley no se ocupa de cualquier tipo de sufrimiento, sino de aquel que es entendido con base en ciertos ideales como injustificado, inmerecido (17). En este caso, además se advierte que las demandas se hacen cargo de un tipo de sufrimiento excepcional, único, fuera de lo esperable. Aquí, lo normal, lo previsible, es la contracara ausente que refleja la 
singularidad del daño sufrido. La puesta en juego de las nociones de trauma y estrés postraumático hablan de ello. La noción de trauma ha pasado de ser un signo de infamia a uno de reconocimiento: las víctimas traumatizadas son personas normales que reaccionan de forma normal ante un hecho extraordinario (Fassin 2014). Y ello se ha constituido en un proceso expandido tanto en países centrales como en Latinoamérica (Arosi 2017; Sarti 2011; Zenobi 2017). El sufrimiento del que las víctimas deben dar cuenta y que debe ser oficialmente reconocido en los instrumentos de reparación de la violencia no se limita al daño físico. El escenario descrito por los peritos técnicos también fue conectado con el sufrimiento psíquico de quienes sobrevivieron a esta situación excepcional. Este adquiere un carácter traumático cuando se trata de una situación particularmente estresante como esta, que

[se] grabó indeleblemente en la psiquis de mi representada: en un ámbito que era una cámara de gas a oscuras [...]. Este cuadro nunca se borra del alma de la víctima que padeció un hecho horrible que nunca va a olvidar, y siguió a eso un estrés postraumático que persistió en el tiempo. (Demanda civil presentada por un sobreviviente)

El manejo de ciertas categorías de percepción y de apreciación irreductibles a los no especialistas, legos y profanos es un principio central de estructuración del campo jurídico. Pero si bien suele prestarse atención destacada al papel del derecho, en contextos muy diversos de violencia diferentes agentes especializados ponen en juego saberes y técnicas que remiten a campos de conocimiento como la arquitectura, la medicina o la psicología. Se trata de una amalgama de saberes que suelen presentarse como auxiliares del saber jurídico: por medio de sus conocimientos, que posiblemente son crípticos para los legos -incluyendo ahora a los operadores judiciales (Schuck 1986)—, ellos logran echar luz y contribuir a la comprensión de los hechos. La certificación conjunta, a través de un entramado de saberes heterogéneo, contribuye a definir un evento crítico como un suceso excepcional y traumático, lo que puede constituirse en un modo de producción de valor. 


\section{Un campo en disputa: los dos modos de la reparación}

Mi punto de partida es que los documentos burocráticos mediante los cuales las víctimas de desastres, violencia estatal o interpersonal solicitan ser reparadas no pueden ser tratados como producciones dadas. Creo en cambio que deben ser abordados como productos sociales, morales y políticos. Las luchas y controversias en el campo jurídico hablan de esa particularidad. Con respecto a las formas de reparación, una de estas luchas está fundamentada sobre la existencia de dos modos en pugna de entender la reparación. La propia historia de la Corte IDH habla de ese proceso.

A partir de la década de los noventa, las reparaciones se fueron convirtiendo en el eje del Sistema Interamericano de Derechos Humanos (SIDH) dentro del cual funciona la Corte IDH. En sus primeras intervenciones, la Corte se limitaba a utilizar el concepto de indemnización, muy ligado a una definición de contenido patrimonial y pecuniario. Si hasta ese momento dominaba una concepción del daño y la compensación en términos económicos, con el paso de los años, la noción de reparación fue desplazando a la de indemnización y se dictaron sentencias que incluían medidas de concientización y memoria, reformas legislativas, ubicación de restos mortales, etc. (Rousset 2011). Este nuevo modo de entender el daño y su reparación es difundido por el orden jurídico transnacional desde hace algunas décadas.

Como parte de la búsqueda de justicia centrada en que el Estado fuera reconocido como responsable por los daños, los abogados sostenían que las exigencias de reparación podían ser llevadas a cabo de modos diferentes. En efecto, frente a las formas centradas en los aspectos pecuniarios, a las que llaman "tradicionales", ellos oponen otras "más actuales" que expresan una mirada "integral" con la que se reconocen como abogados y como víctimas. La primera postura es identificada por ellos con el derecho de daños propio del marco civil local, mientras que las segundas serían aquellas generadas en el marco de la justicia transicional y divulgadas desde los organismos transnacionales. Estas diferentes posiciones sobre la reparación forman parte de una lucha en el campo jurídico en el que los abogados se ubican como combatientes, como profesionales comprometidos con las formas de reparación más actuales:

los jueces están formados en la ecuación económica de los daños y perjuicios, la figura del lucro cesante, el uso de baremos... Las demandas que elaboramos nosotros van en contra de este tipo de demandas. 
Estamos llevando adelante una batalla con jueces formados en ese esquema clásico. (Abogado, entrevista, mayo de 2016)

A modo de diferenciación de quienes estarían formados en la mirada clásica, pecuniaria, estos profesionales rescatan la perspectiva de la integralidad y asumen posiciones innovadoras al articularla en el contexto del derecho civil local. En ese camino debe comprenderse su utilización de la definición de víctima, proporcionada por la ONU (2005), que forma parte de la mirada integral. Allí se afirma que víctima es "toda persona que haya sufrido daños, individual o colectivamente, incluidas lesiones físicas o mentales, sufrimiento emocional, pérdidas económicas o menoscabo sustancial de sus derechos fundamentales”. En la elaboración de demandas indemnizatorias, esas variadas formas de daño son traducidas a rubros indemnizatorios entre los que pueden encontrarse algunas categorías clásicas vinculadas al paradigma economicista de la reparación económica, tales como daño psicológico, valor vida o daño moral. Pero junto a aquellas categorías tradicionales, en las demandas de las víctimas del incendio se retoma la definición de víctima aportada por la ONU y se la sitúa en relación con otras categorías como el rubro proyecto de vida, que también están basadas en la mirada integral difundida por el orden transnacional ${ }^{8}$.

La categoría daño al proyecto de vida fue reconocida por primera vez por la Corte IDH en el marco del caso María Elena Loayza Tamayo vs. Perú del año 1997. La aparición de determinadas figuras, conceptos y tipologías jurídicas abre un campo de posibilidades novedoso al establecer que existe un cierto bien que debe protegerse (Ross 2014). Según la Corte IDH (1998), el rubro indemnizatorio proyecto de vida "atiende a la realización integral de la persona afectada, considerando su vocación, aptitudes, circunstancias, potencialidades y aspiraciones, que le permiten fijarse razonablemente determinadas expectativas y acceder a ellas”. En el campo jurídico existe una controversia acerca de la claridad y fundamento doctrinario de esta categoría, así como sobre la posibilidad de resarcirla económicamente. Además, al analizar su autonomía conceptual, algunos juristas sostienen que puede asimilarse al daño moral o al psíquico (Aráoz 2015)․ personalísimos de la víctima, de su integridad personal, su salud psicofísica, sus afecciones espirituales legítimas y las que resultan de la interferencia en su proyecto de vida". 
Las posibilidades abiertas por la nueva categoría proyecto de vida fueron retomadas por los abogados de las víctimas del incendio. Su incorporación en las demandas amplió la noción de daño más allá de lo material, pero también de los aspectos psicosomáticos y del daño moral. Por esa vía, también se extendió la esfera de las personas afectadas; es decir, ya no se trata solo de aquel directamente perjudicado sino, con base en una conceptualización que relaciona familia, parentesco y sufrimiento, de formas de daño más extendidas: "La frustración definitiva del proyecto de vida, de esa planificación humana, impacta de manera determinante en ese núcleo familiar" (demanda civil presentada por familiares de un fallecido). Al poner en el centro esta figura jurídica novedosa, ellos se distancian del "simple daño" a través del cual se exige una reparación en dinero y se esfuerzan por reorientar el dispositivo de acuerdo con ciertas expectativas más amplias de justicia. Si bien a priori el dispositivo indemnizatorio se basa en la compensación económica, los abogados pretenden situar en el eje de la discusión no tanto el valor monetario del daño, sino la responsabilidad estatal por el sufrimiento que puede alcanzar a toda una familia y orientar el dispositivo de acuerdo con sus expectativas de justicia.

Aunque la construcción de nexos entre hechos pasados y sufrimiento actual a través de categorías jurídicas forma parte de una política de las causas, esa construcción es llevada adelante en diálogo con las ideas de los abogados de las víctimas acerca de la justicia y de su compromiso con el movimiento de lucha, es decir, con la causa política. A través de ese trabajo jurídico que se mueve entre los usos legitimados y los intentos de estirar y reorientar las clasificaciones, ciertos conceptos y categorías del derecho civil son adaptados, impugnados, resignificados y manipulados en circunstancias concretas.

Técnicas, teorías, conceptos, categorías que están informados por posiciones morales y políticas son las herramientas que los expertos ponen en juego. De ahí la importancia de traer a escena a los productores de las demandas y de incorporar tanto su concepción del derecho como su posición en el campo político más amplio del movimiento de lucha.

a través de su voto que el concepto en cuestión "adolece de falta de claridad y fundamento jurídico" (Corte IDH 1998) y que puede asimilarse al daño moral o al psíquico. 


\section{La demostración del daño y su valuación}

Las formas de valuación económica incorporan todo tipo de suposiciones sobre las relaciones sociales (Carruthers 2010; Zelizer 2005). Como ha demostrado numerosa literatura sobre el tema (Lacerda 2015; Luzzi 2015; Tello 2003), en las discusiones y debates acerca de la reparación a víctimas de violencia en Latinoamérica el dinero ocupa un lugar destacado. En función de estas cuestiones, el dinero es visto como un medio inadecuado de reparación, así como contaminante, un medio que ensucia, mancha a quien lo acepta.

En lo que hace a la valuación del daño, los abogados comprometidos con la causa de las víctimas del incendio apuntaron contra la perspectiva jurídica conocida como análisis económico del derecho, a la que acusan de ser reduccionista. Se trata de una corriente de pensamiento que aplica métodos propios de la economía en el razonamiento jurídico. En contra de la idea de que "todo tiene un precio", uno de los abogados, quien es padre de un joven fallecido en el incendio, sostiene:

El problema es mensurar económicamente algo inconmensurable. La incapacidad que genera haber perdido un dedo con una sierra eléctrica está medida en los baremos de derecho laboral, pero eso no es comparable a haberse quedado encerrado en un lugar que se incendió, se apagó la luz y que parecía la cámara de gas de Auschwitz, como ocurrió en el incendio de Cromañón. Operar con esa lógica economicista sería creer que un hijo es lo mismo que un auto, como si yo pudiera perder mi hijo y comprar otro con dinero. Eso es falso. Esa teoría contradice el hecho de ser víctima, porque te ubica en el lugar de alguien que solo pide dinero, pero la reparación para una víctima no surge de una ecuación algebraica según ciertos rubros indemnizatorios. El dinero no te repara nada. Nosotros pedimos justicia, que el Estado se haga cargo. Eso es lo que tiene verdadera capacidad reparatoria. (Abogado, entrevista, mayo de 2016)

Como puede verse, la frontera entre lo que tiene y lo que no tiene precio marca una diferencia entre situaciones como accidentes laborales que implican la pérdida de un miembro y situaciones como el incendio que conducen a perder la vida de un modo especialmente trágico. Desde esa perspectiva, las posiciones derivadas del análisis económico del derecho que pretenden calcular y fijar objetivamente el valor del daño no serían adecuadas para tramitar circunstancias como las del incendio y otras similares.

Dicha frontera - entre lo que puede admitir valuación de algún tipo y lo que no- es producto de la oposición entre mundos hostiles (Zelizer 2005): por un lado, el mundo privado de los afectos, el amor y las relaciones familiares y, por otro lado, el mundo público del mercado, regido por las reglas de la competencia 
y el individualismo. La oposición entre familia y mercado es constitutiva de nuestra doxa occidental, está estrechamente relacionada con el desarrollo histórico de lo privado y lo público como esferas de la vida social separadas entre sí (cfr. Collier, Rosaldo y Yanagisako 1997). Según Bourdieu (1997), aquella doxa define la familia como un universo fundado sobre un conjunto de prescripciones normativas que la (re)presentan como el lugar de la solidaridad, la confianza y el don. En suma, del desinterés.

Tanto las críticas a la orientación pecuniaria de la reparación -de las que me he ocupado en secciones previas - como las dirigidas al análisis económico del derecho muestran los desajustes entre la orientación y finalidad de los dispositivos indemnizatorios tradicionales disponibles y las propias elaboraciones de los demandantes para pensar una indemnización justa. Tal como han mostrado Barbot, Winance y Parizot (2015) para el caso de los dispositivos reparatorios, el dispositivo puede ser objeto de críticas y de intentos de reformularlo o, al menos, de reorientarlo. En el caso de reparaciones a víctimas de violencia suele observarse que, frente a los conflictos y dilemas desatados por la posibilidad de poner precio a lo sagrado (la vida, la sangre), hay un esfuerzo de las víctimas y de sus abogados por destacar la intención de utilizar el dispositivo de reparación como un mecanismo que contribuye a alcanzar justicia a través de la responsabilización estatal. De esto habla el hecho de que se coloquen en el centro de los pedidos indemnizatorios categorías como daño moral y daño al proyecto de vida que, a diferencia de otras como daño físico o lucro cesante, no requieren ser demostradas y son de difícil valuación monetaria.

Por un lado, en lo que respecta al daño moral, en derecho civil se asume que se trata de un tipo de daño que no debe ser demostrado, una cuestión que no necesita certificación alguna: "la víctima de violaciones a los derechos humanos [...] no debe acreditar haber sufrido daño moral, toda vez que 'resulta evidente, pues es propio de la naturaleza humana que [...] experimente dolores corporales y un profundo sufrimiento"” (demanda civil presentada por una sobreviviente). Por su parte, en lo relativo al daño al proyecto de vida, existen controversias sobre la demostración y la valuación, en consonancia con las controversias sobre su autonomía conceptual y su resarcimiento a las que me referí. La Corte IDH no ha establecido principios lógicos y claros que permitan evaluar con precisión este tipo de daño y su valuación (Aráoz 2015).

Mientras que las formas que los abogados de las víctimas del incendio definen como tradicionales parecen brindar herramientas como fórmulas, baremos, proyecciones, etc. para calcular el daño y su reparación pecuniaria, aquellas que los abogados llaman las nuevas corrientes ya no se esfuerzan por valuar ese tipo de situaciones y reconocen esa dificultad explícitamente aceptando la 
arbitrariedad de las cifras. En lo que respecta a la determinación del importe por el rubro valor vida, las demandas refieren a jurisprudencia de otros casos en los que se ha

“desechado la posibilidad de aplicar módulos de cálculo financiero, al declararse, con agudeza, que un padre, un hijo, un esposo o una esposa no constituyen para los suyos un capital que se mida por la renta que pueda dar...”; [y consideran que] la norma aplicable [...] deja librado "a la prudencia de los jueces fijar el monto de la indemnización (art. 1084 parte $2^{\circ}$ Código Civil de la Nación)”. En virtud de lo expuesto, considero que el daño generado por la pérdida de la vida de A.B. debe ser valuado en la suma de pesos $\$ 1.000 .000$ (un millón de pesos) para cada uno de sus padres. (Demanda civil presentada por familiares de un fallecido)

Como se ha señalado para otros contextos, a diferencia de las pérdidas que son tenidas como esperables o habituales y que pueden ser medidas por el valor de mercado, o el establecimiento de medidas promedio, desde la óptica de los actores del universo jurídico las pérdidas que son tenidas como "inusuales” no pueden ser fácilmente "normadas” y la falta de conformidad a un patrón o mercado hace que para ellos sea más difícil establecer la compensación (Ross 2014).

Si bien las demandas se refieren en reiteradas oportunidades a la dificultad, la imposibilidad y la arbitrariedad de las formas de valuación, se establecieron algunos criterios de control basados en eventos similares sobre los que existe amplia jurisprudencia, como el atentado terrorista a la Asociación $\mathrm{Mu}$ tual Israelita Argentina (AMIA) de Buenos Aires o la explosión de una fábrica de armamento militar ${ }^{10}$. A partir de allí, es posible establecer montos mínimos a pagar por debajo de los cuales se ofendería la dignidad de las víctimas ${ }^{11}$. Como han

10 En el año 1994 hubo un atentado con explosivos en la sede de la mutual de instituciones judías argentinas AMIA, en el que murieron 85 personas. El hecho desató un gran movimiento de protesta y reivindicación de justicia que recorrió la sociedad argentina durante una década. Entre el 2000 y el 2004 se realizó un juicio que finalizó con la absolución de todos los acusados y la revelación de un amplio encubrimiento que incluía a funcionarios judiciales, al presidente de la nación, al presidente de una de las principales organizaciones de la comunidad judía argentina, a policías y a servicios de inteligencia. Otra explosión ocurrió en 1995, esta vez en una fábrica de armamentos militares, ocasión en la que murieron siete personas. En 2014 se dictó sentencia condenatoria a cuatro altos funcionarios militares, bajo el cargo de haber hecho estallar la fábrica con el objetivo de ocultar el contrabando de armas a Ecuador y Croacia.

11 El primero de estos mecanismos de control se basó en una fórmula que consideraba los montos que el propio Estado había ofrecido a las víctimas como compensación - lo cual fue rechazado (ver más adelante)- y una actualización según el Índice de Precios al Consumidor, lo que aumentaba esa cifra en un $50 \%$. El segundo mecanismo recuperaba las fórmulas utilizadas para indemnizar a las víctimas del atentado y de la explosión mencionada: prescribían para los familiares "un beneficio extraordinario equivalente a la remuneración mensual de los agentes Nivel A, Grado 0, del Escalafón del Personal del Sistema Nacional de Empleo Público [...] por el coeficiente cien (100)" (demanda civil presentada por familiares de un fallecido). 
mostrado otras investigaciones, las víctimas de violencia pueden reorientar los dispositivos de compensación en función de las expectativas de justicia (Luzzi 2015; Tello 2003). En este caso, los abogados llevan a cabo ese trabajo al imponer categorías de daño amplias, abarcadoras, que no deben ser demostradas y que son de una dudosa, imprecisa o imposible valuación.

\section{La reparación económica y la movilización política}

Durante la década de los noventa, algunos Estados latinoamericanos que habían atravesado periodos dictatoriales pusieron en marcha dispositivos de reparación económica e indemnizaron a las víctimas del accionar represivo (Aydos 2002; Guembe 2006; Rosito y Damo 2014). Tal como se ha señalado en la sección previa, la bibliografía temática muestra que las dificultades de "poner precio" se articulan con una mirada sobre el dinero que puede ser visto como un agente que corrompe, que contamina. Esta idea está sostenida sobre una crítica de larga data: en el caso de Marx, según Carruthers (2010), apuntaba a que el dinero despersonalizaba y reducía las lógicas de las relaciones sociales preexistentes a las del mercado; según Zelizer (1994), Simmel realizaba una crítica similar que esta autora puso en cuestión al mostrar los sentidos atribuidos al dinero en la vida cotidiana.

En los casos de reparaciones a víctimas de violencia en los que el Estado es el responsable de su desgracia, los dilemas sobre los pagos indemnizatorios y la suciedad del dinero adquieren particular dramatismo: esos pagos pueden ser entendidos como intentos de "comprar el silencio". Desde inicios de 1980, la actividad de los organismos de derechos humanos en Argentina estuvo centrada en la búsqueda de la verdad y en las acciones penales concomitantes, por lo que las demandas civiles no formaron parte de las estrategias colectivas que constituían a las víctimas como un colectivo que exigía justicia (Luzzi 2015; Tello 2003; Vecchioli 2005). Aunque la mayoría de los familiares de las víctimas aceptó la reparación, no faltaron cuestionamientos morales y políticos que se veían reflejados en las formas de nombrar ese dinero como plata quemada, dinero maldito

En cambio, los sobrevivientes de esos hechos con lesiones gravísimas recibieron un $70 \%$ y por lesiones graves, un $60 \%$. Como tercer y último modo de control, se solicitó que al momento de la sentencia se actualizara el monto de pago y que este fuera equivalente a la cifra estimada en dólares estadounidenses - a la que los abogados se referían como moneda estable y dura-. 
o mal habido (Guembe 2006). Así fue como en la década de los noventa, en el caso de los organismos de derechos humanos de Argentina, el dinero se constituyó en un clivaje que articuló conflictos entre organizaciones. Mientras que algunos familiares de desaparecidos aceptaron cobrar el pago de una compensación económica prevista por ley, las Madres de Plaza de Mayo rechazaron ese dinero bajo el lema “Las que cobran las indemnizaciones se prostituyen”. Quienes condenaban el cobro consideraban que "la fuerza de la cosa dada” por el Estado implicaba entregar a cambio la lucha (Tello 2003).

En el caso del Movimiento Cromañón, la mayor parte de los familiares siempre estuvo muy informada acerca de la causa penal: semanalmente se realizaban reuniones con los abogados. Las víctimas consideraron que la presentación de demandas civiles era parte de sus derechos como afectadas y creían que se trataba de un dinero justo. En cambio, rechazaron el ofrecimiento de una compensación económica que realizó el Estado que las obligaba a dejar de lado las presentaciones civiles, por verlo como un intento de silenciar sus reclamos penales. De todos modos, al igual que en los casos previamente mencionados, las acciones civiles nunca fueron objeto de estrategias discutidas y elaboradas colectivamente y no se habló públicamente del tema. Desde la óptica jurídica, la idea de que se trata de una cuestión individual se corresponde con la división en el campo jurídico entre derecho privado y derecho público: “A muchos familiares les generaba dilemas reclamar plata por sus hijos. Ese tema era una cuestión de derecho privado; por eso, no armamos reuniones grupales para debatir el tema. Era mucho más importante la cuestión penal que la civil” (abogada, entrevista, agosto de 2016).

Así fue como, en un contexto de movilización y lucha política, la cuestión civil quedó reducida a un lugar secundario. Por ese motivo, se trataba de un tema del que nadie hablaba en público ni en las conversaciones informales en privado. Incluso, los propios interesados que habían presentado demandas desconocían las particularidades de la demanda civil que habían presentado los abogados en su representación o cuál era el estado de avance o la situación del pedido indemnizatorio realizado.

No obstante, al igual que en el caso de las víctimas de terrorismo de Estado, la cuestión funcionó como un disparador para lanzar acusaciones y articular algunas dinámicas en el nivel de la lucha política. Así, si bien era visto como un dinero justo, en algunos casos se objetaba a quienes querían cobrarlo y se los trataba como aprovechadores. Estas acusaciones ocurrían especialmente en el caso de los sobrevivientes del incendio que exigían indemnizaciones, pero que no habían iniciado acciones en el plano penal: se los acusaba de buscar dinero en lugar de buscar justicia. Del total de 1.600 demandas civiles presentadas, en 850 casos las víctimas también se presentaron como querellantes en la justicia 
penal. Es decir, que en 750 casos solo se presentaron como demandantes civiles. Si bien los pedidos de indemnizaciones no representaron un conflicto ético, ya que era un dinero considerado como justo y merecido, en algunas ocasiones se ha denunciado a algunas de esas 750 personas que han renunciado a ser querellantes penales y que "solo buscan dinero a costa de los muertos". Ese es el caso de la organización Transformemos Nuestras Vidas (TNV), una asociación civil conformada por sobrevivientes del incendio.

Las primeras apariciones públicas de TNV sucedieron en mayo del 2006 cuando hicieron público su primer boletín de difusión de actividades, divulgado por correo electrónico ${ }^{12}$. Allí se señalaba a modo informativo que los sobrevivientes que pretendieran iniciar demandas civiles no estaban obligados a presentarse como querellantes en la acción penal, pero que "es conveniente hacerlo para poder acreditar mejor la concurrencia el día del recital y los perjuicios sufridos por sus consecuencias. Eso nos facilita la prueba en el juicio civil”. Esta forma de entender la cuestión invertía el interés de las víctimas movilizadas en las calles que exigían justicia penal y que dejaban al dispositivo de reparación económica en segundo plano. De un modo inverso, estos sobrevivientes consideraban la querella penal como una simple "ventaja", una prueba más para poder alcanzar el fin último y más relevante para ellas de obtener una indemnización. En varias ocasiones se sugirió que se trataba de falsas víctimas que pretendían ganar dinero con la masacre a costa de dejar de lado el reclamo de justicia. Como con las acusaciones de hechicería, estas dejaban expuesta una teoría moral (Zenobi 2010).

A diferencia del modo en que ha sido tratada esta cuestión en otros casos, aquí el dilema moral que representan las indemnizaciones no es tanto un producto de aquella oposición entre representaciones e ideales, ya que la oposición ideal entre "mundos hostiles" no despertó dificultades cuando las víctimas pidieron justicia (causa penal) y dinero (causa civil) — que fue visto como un dinero merecido, justo-. Lejos de ser meramente un asunto representacional, esta oposición no se traduce automáticamente en un conflicto ético para los actores. El cisma entre verdaderas víctimas y falsas víctimas solo se expresó en el caso de quienes se limitaron a pedir indemnizaciones y renunciaron a la lucha pública por justicia y al juicio penal. 


\section{Cierre: la Víctima, las víctimas y sus especialistas}

En numerosos contextos de victimización se observa un proceso opuesto y complementario en el que se expresa el carácter particular pero a la vez más genérico de la postura de las víctimas (Gatti 2017). Ellas se posicionan desde el dramatismo de su situación particular como un modo de producir el valor social de la catástrofe vivida, al mismo tiempo que construyen conexiones con otro tipo de situaciones a las que consideran asimilables. Resulta central el papel que desempeñan los abogados, sin cuya participación las expectativas de justicia no podrían traducirse al campo jurídico. Como he mostrado, en ese campo aparentemente autónomo se dan las luchas entre los especialistas que defienden formas diferentes de entender la reparación. Sin embargo, ellos, "adversarios objetivamente cómplices, se ayudan mutuamente: compiten pero sobre bases comunes” (Bourdieu 2000, 172).

El papel de los abogados comprometidos que hacen de su compromiso político una condición de su actividad profesional - por ejemplo, los abogados de derechos humanos (Vecchioli 2006) - muestra la porosidad del campo jurídico: al igual que en otros casos de reparación de la violencia, la justicia civil (reparación) puede ser vista como un actor que puede contribuir a hacer justicia (retribución) ${ }^{13}$. De modo similar a lo que se observa en otras experiencias, frente a esos desajustes entre los objetivos institucionales formales de los mecanismos y las expectativas de las personas, los abogados realizan su trabajo de reorientar el dispositivo reparatorio para acercarlo al cumplimiento de sus expectativas. Desde su lugar de abogados y de víctimas, la manipulación de las herramientas jurídicas en el marco del derecho civil está en función de la causa y política y del ideal de justicia que se centra en la responsabilización del Estado.

Contra la crítica clásica según la cual el dinero influye negativamente en las relaciones sociales, se ha sostenido que el dinero afecta lo social tanto como lo social afecta al dinero (Carruthers 2010; Zelizer 2005). Como ha mostrado Fourcade (2016) para la valuación de los desastres naturales, aquí también puede notarse cómo lo emocional, lo moral y lo afectivo relativo al carácter "sagrado" de ciertas relaciones sociales modelan las solicitudes que forman parte del dispositivo jurídico de indemnización económica. Las nociones sobre la letalidad

13 En un sentido inverso, cuando la justicia penal es vista como un mecanismo de reparación simbólica, ocurre lo opuesto. En Argentina, este último caso está representado por el cruce entre trauma e impunidad, del que se han ocupado numerosos autores y profesionales "psi" que cruzan el campo de la salud mental con el de los derechos humanos (Zenobi 2017). 
del veneno, el sufrimiento extendido hacia la familia, el sufrimiento psíquico, el calificativo de masacre y hecho notorio, etc., son las categorías morales que vienen a modelar y justificar las categorías técnicas jurídicas y las formas de poner precio.

Aquí intenté mostrar que, así como los dispositivos hacen personas, las personas hacen dispositivos. Si bien el campo jurídico suele representarse bajo la idea de "autonomía” en relación con las presiones externas, he sostenido que el rumbo que toman sus dispositivos puede estar relacionado con las causas políticas en las que se expresan las expectativas de justicia que fundamentan las prácticas jurídicas de los abogados comprometidos. Ocurre así una convergencia entre la acción de las víctimas movilizadas y la de los profesionales cuyos saberes pueden ser un gran recurso a la hora de nutrir la causa pública (Dodier 2009; Fillion y Torny 2015).

El hecho de que las demandas civiles fueran un tema "personal” del que no se hablaba en público sugiere que para las víctimas era un tema tabú, rodeado de prohibiciones y reglas relativas a cuándo y con quiénes podía tratarse la cuestión. Desde hace más de un siglo, los antropólogos sabemos que la existencia de tabúes y prescripciones remite a una forma de producir valor social: como ha mostrado magistralmente Radcliffe-Brown (1974) al analizar las formas de producción de valor, las situaciones como las crisis vitales (nacimientos, casamientos, muertes) son socialmente valoradas debido a que son ritualizadas y no al revés. A diferencia de la perspectiva nativa que ve en la vida y el sufrimiento humano cuestiones sagradas invaluables, si ponemos la mirada en una escala temporal más larga, puede sugerirse que - como muestran Zelizer (2005) o Fourcade (2016) para otros dispositivos-, el dinero y las demandas civiles serían mecanismos que contribuyen a la sacralización de determinadas relaciones sociales. En este trabajo he procurado exponer que, más allá de evaluar la eficacia de los mecanismos de reparación, desde una perspectiva sociológicamente distanciada es posible echar luz sobre los supuestos, las relaciones de poder, las asimetrías y las evaluaciones morales que ponen en juego los especialistas y los legos que los hacen funcionar.

\section{Referencias}

Aráoz Falcón, Candelaria. 2015. "Dano ao 'projeto de vida’. Um novo horizonte às reparações dentro do Sistema Interamericano de Direitos Humanos?”. Revista Direitos Humanos e Democracia 3 (5): 47-88. https://doi.org/10.21527/2317-5389.2015.5.47-88 
Arosi, Ana Paula. 2017. "Ativismo de vítimas do incêndio na boate Kiss: evento traumático, causa pública e conflitos morais”. Papeles del CEIC. International Journal on Collective Identity 2017/1, papel 168. http://dx.doi.org/10.1387/pceic.16911

Aydos, Valéria. 2002. "Vidas marcadas: experiências de tortura nas trajetórias de presos políticos no periodo da Ditadura Militar em Porto Alegre, Rio Grande do Sul”. Tesis de Maestría en Antropología Social, UFRGS, Porto Alegre.

Bandes, Susann. 1996. "Empathy, Narrative, and Victim Impact Statements". The University of Chicago Law Review 63 (2): 361-412. https://doi.org/10.2307/1600234

Barbot, Janine y Nicolas Dodier. 2015. “Victims’ Normative Repertoire of Financial Compensation: The Tainted hGH Case”. Human Studies 38 (1): 81-96. https://doi.org/10.1007/ s10746-014-9330-4

Barbot, Janine, Mariel Winance e Isabelle Parizot. 2015. "Imputer, reprocher, demander réparation. Une sociologie de la plainte en matière médicale”. Sciences Sociales et Santé 33: 77-105. https://doi.org/10.3917/sss.332.0077

Barthe, Yannick. 2010. “Causa política y 'política de las causas’. La movilización de los veteranos de ensayos nucleares franceses”. Revista de la Carrera de Sociología 7 (7): 264-302. https://publicaciones.sociales.uba.ar/index.php/entramadosyperspectivas/article/ view/2602

Boltanski, Luc, Yann Darré y Marie-Ange Schiltz. 1984. "La dénonciation”. Actes de la Recherche en Sciences Sociales 51: 3-40. https://doi.org/10.3406/arss.1984.2212

Bourdieu, Pierre. 1997. "Espíritus de familia”. En Razones prácticas: sobre la teoría de la acción, 126-138. Barcelona: Anagrama.

—. 2000. "Elementos para una sociología del campo jurídico”. En La fuerza del derecho, editado por Pierre Bourdieu y Gunter Teubnar, 153-220. Bogotá: Siglo del Hombre.

Boyer, Dominique. 2008. "Thinking through Anthropology of Experts”. Anthropology in Action 15 (2): 38-46. https://doi.org/10.3167/aia.2008.150204

Carruthers, Bruce. 2010. “The Meanings of Money: A Sociological Perspective”. Theoretical Inquiries in Law 11 (1): 51-74. https://www7.tau.ac.il/ojs/index.php/til/article/view/733

Chaumont, Jean-Michelle. 2000. "Du culte des héros a la concurrence des victimes”. Criminologie 33: 167-183. https://doi.org/10.7202/004712ar

Collier, Jane, Michelle Z. Rosaldo y Sylvia Yanagisako. 1997. “¿Is There a Family? New Anthropological Views”. En The Gender/Sexuality Reader, editado por Roger N. Lancaster y Micaela Di Leonardo, 71-81. Nueva York; Londres: Routledge.

Corte IDH (Corte Interamericana de Derechos Humanos). 1998. Caso Loayza Tamayo. Sentencia del 27 de noviembre. San José, Costa Rica: Corte IDH.

Das, Veena. 1995a. Critical Events: An Anthropological Perspective on Contemporary India. Oxford: Oxford University Press.

-. 1995b. "Suffering, Legitimacy and Healing: The Bhopal Case". En Critical Events: An Anthropological Perspective on Contemporary India, 137-175. Oxford: Oxford University Press. 
Dodier, Nicolas. 2009. “Experts et victimes face à face”. En Mobilisations de victimes, editado por Sandrine Lefranc y Lilian Mathieu, 29-36. Rennes: Presses Universitaires de Rennes.

Dodier, Nicolas y Janine Barbot. 2017. “A força dos dispositivos”. Revista Sociedade e Estado 32 (2): 487-518. https://doi.org/10.1590/s0102-69922017.3202010

Fassin, Didier. 2014. "De l'invention du traumatisme à la reconnaissance des victimes. Genèse et transformations d'une condition morale”. Vingtième Siècle. Revue d'Histoire 123 (3): 161-171. https://doi.org/10.3917/vin.123.0161

Feldman, Eric. 2000. "Blood Justice: Courts, Conflict, and Compensation in Japan, France, and the United States”. Law \& Society Review 34 (3): 651-701. http://doi.org/10.2307/3115140

Fernández Sessarego, Carlos. 2003. “El daño al 'proyecto de vida' en la jurisprudencia de la Corte Interamericana de Derechos Humanos”. Derecho PUCP 56: 659-700. http://revistas. pucp.edu.pe/index.php/derechopucp/article/view/10593

Fillion, Emaneulle y Didier Torny. 2015. "De la réparation individuelle à l'élaboration d'une cause collective. L’engagement judiciaire des victimes du distilbène”. Revue Française de Science Politique 65 (4): 583-607. https://doi.org/10.3917/rfsp.654.0583

Fourcade, Marion. 2016. "Dinero y sentimientos: valuación económica y la naturaleza de la 'Naturaleza”. Apuntes de Investigación del CECyP, 27: 69-125. http://www.apuntescecyp. com.ar/index.php/apuntes/article/view/596

Gatti, Gabriel. 2013. "Moral Techniques. Forensic Anthropology and Its Artifacts for Doing Good”. Sociología y Tecnociencia/Sociology and Technoscience 3 (1): 12-31. https://1library. co/document/q05v3mky-moral-techniques-forensic-anthropology-artifacts-doing-good. html

-. 2017. Un mundo de víctimas. Barcelona: Anthropos.

Guembe, María José. 2006. "Economic Reparations for Grave Human Rights Violations: The Argentinean Experience”. En Handbook of Reparations, editado por Pablo de Greiff, 21-54. Nueva York: Oxford University Press.

Guglielmucci, Ana. 2015. “Transición política y reparación a las víctimas del terrorismo de Estado en la Argentina: algunos debates pendientes”. Taller. Revista de Sociedad, Cultura y Política en América Latina, 2. época, 4 (5): 24-42. https://ri.conicet.gov.ar/handle/11336/51280

Gutiérrez, Martha. 2019. "Negar el pasado: reparaciones en Guatemala y El Salvador”. Colombia Internacional 97: 175-209. https://doi.org/10.7440/colombiaint97.2019.07

Henry, Emanuelle. 2007. Amiante: un scandale improbable. Sociologie d'un problème public. Rennes: Presses Universitaires de Rennes.

Jensen, Steffen y Henrik Ronsbo. 2014. "Introduction. Histories of Victimhood: Assemblages, Transactions, and Figures”. En Histories of Victimhood, editado por Steffen Jensen y Henrik Ronsbo, 1-22. Filadelfia: University of Pennsylvania Press.

Jiménez, William. 2013. "Origen y evolución de las teorías sobre la responsabilidad estatal”. Diálogos de Saberes. Investigaciones y Ciencias Sociales 38: 63-78. https://doi. org/10.18041/0124-0021/dialogos.38.2013.1832 
Lacerda, Paula. 2015. Meninos de Altamira: violência, 'luta' política e administração pública. Río de Janeiro: Garamond.

Lefranc, Sandrine. 2009. "La professionnalisation d'un militantisme réformateur du droit: l'invention de la justice transitionnelle”. Droit et Société 73: 561-589. https://doi.org/10.3917/ drs.073.0561

Lenoir, Remi. 1993. “Objeto sociológico y problema social”. En Iniciación a la práctica sociológica, editado por Patrick Champagne, Remi Lenoir, David Merllié y Louis Pinto, 57-102. Ciudad de México: Siglo XXI.

Luzzi, Mariana. 2015. "Pagar para reparar. Debates públicos y dilemas privados ante las políticas de reparación económica a las víctimas del terrorismo de Estado en Argentina”. En Muerte, política y sociedad en la Argentina, editado por Sandra Gayol y Gabriel Kessler, 251-276. Buenos Aires: Edhasa.

Merry, Sally Engle. 2006. "Transnational Human Rights and Local Activism: Mapping the Middle”. American Anthropologist 108 (1): 38-51. https://doi.org/10.1525/aa.2006.108.1.38

Neiburg, Federico y Mariano Plotkin. 2004. Intelectuales y expertos: la constitución del conocimiento social en Argentina. Buenos Aires: Paidós.

Oliveira, Lucas Cravo de. 2020. "Fronteiras improváveis entre tempos e direitos: constitucionalismo compartilhado entre os sistemas de justiça estatal e Mẽbêngôkre Kayapó no acidente do Gol 1907”. Tesis de Doctorado en Derecho, Universidade de Brasília, Brasilia.

ONU (Organización de las Naciones Unidas). 1997. La administración de la justicia y los derechos humanos de los detenidos: la cuestión de la impunidad de los autores de violaciones de los derechos humanos (civiles y políticos). Ginebra: ONU/Comisión de Derechos Humanos.

-. 2005. Principios y directrices básicos sobre el derecho de las víctimas de violaciones manifiestas de las normas internacionales de derechos humanos y de violaciones graves del derecho internacional humanitario a interponer recursos y obtener reparaciones (Resolución 60/147). Nueva York: Asamblea General de la ONU. https://www.ohchr.org/sp/professionalinterest/pages/remedyandreparation.aspx

Parascandola, Mark. 1996. "Evidence and Association: Epistemic Confusion in Toxic Tort Law”. Philosophy of Science 63: 168-176. https://doi.org/10.1086/289949

Petryna, Adriana. 2004. "Biological Citizenship: The Science and Politics of Chernobyl-Exposed Populations”. Osiris 19: 250-265. https://doi.org/10.1086/649405

Radcliffe-Brown, Arthur. 1974. Estructura y función en la sociedad primitiva. Barcelona: Península.

Redfield, Peter. 2006. "A Less Modest Witness: Collective Advocacy and Motivated Truth in a Medical Humanitarian Movement”. American Ethnologist 33 (1): 3-26. https://doi. org/10.1525/ae.2006.33.1.3

Revet, Sandrine. 2007. Anthropologie d'une catastrophe: les coulées de boue de 1999 au Venezuela. París: Presses Sorbonne Nouvelle.

Rosito, João Baptista Alvares y Arlei Sander Damo. 2014. “A reparação por perseguição política e os relatos de violência nas caravanas da anistia”. Horizontes Antropológicos 20 (42): 181-212. https://doi.org/10.1590/S0104-71832014000200008 
Ross Meyer, Linda. 2014. "Suffering the Loss of Suffering: How Law Shapes and Occludes Pain”. En Knowing the Suffering of Others: Legal Perspectives on Pain and Its Meanings, editado por Austin Sarat, 15-61. Alabama: The University of Alabama Press.

Rousset Siri, Andrés. 2011. "El concepto de reparación integral en la jurisprudencia de la Corte Interamericana de Derechos Humanos”. Revista Internacional de Derechos Humanos, 1: 59-79. http://www.revistaidh.org/ojs/index.php/ridh/article/view/6

Sarti, Cynthia. 2011. "A vítima como figura contemporânea”. Caderno CRH 24 (61): 51-61. http://dx.doi.org/10.1590/S0103-49792011000100004

Schuck, Peter. 1986. Agent Orange on Trial: Mass Toxic Disasters in the Courts. Cambridge: The Belknap Press of Harvard University Press.

Silva, Telma Camargo da. 2015. "Tracing Identities through Interconnections: The Biological Body, Intersubjective Experiences and Narratives of Suffering”. Vibrant Virtual Brazilian Anthropology 12 (1): 260-289. http://dx.doi.org/10.1590/1809-43412015v12n1p260

Tello, Mariana. 2003. "La fuerza de la cosa dada: derechos humanos, política y moral en las 'indemnizaciones' a las víctimas del terrorismo de Estado en Argentina”. En Antropologia e Direitos Humanos, vol. 2, organizado por Roberto Kant de Lima, 37-74. Río de Janeiro: Universidade Federal Fluminense.

Todeschini, Maya. 1999. "Illegitimate Sufferers: A-Bomb Victims, Medical Science, and the Government”. Daedalus 128 (2): 67-100. http://www.jstor.org/stable/20027555

Torpey, John. 2001. "Making Whole What Has Been Smashed: Reflections on Reparations". The Journal of Modern History 73 (2): 333-358. https://doi.org/10.1086/321028

Vecchioli, Virginia. 2005. "La nación como familia. Metáforas políticas en el movimiento argentino por los derechos humanos”. En Cultura y política en etnografías sobre la Argentina, editado por Sabina Frederic y Germán Soprano, 241-270. Quilmes: UnQui; Prometeo.

—. 2006. "A luta pelo direito: engajamento militante e profissionalização dos advogados na causa pelos direitos humanos na Argentina”. Tesis de Doctorado en Antropología, Universidade Federal do Rio de Janeiro, Río de Janeiro.

Visacovsky, Sergio, ed. 2011. Estados críticos: la experiencia social de la calamidad. La Plata: Ediciones Al Margen.

Zelizer, Vivianne. 1994. The Social Meaning of Money. Princeton, NJ: Princeton University Press.

—. 2005. La negociación de la intimidad. Ciudad de México: Fondo de Cultura Económica.

Zenobi, Diego. 2010. “O antropólogo como “espião”: das acusações públicas à construção das perspectivas nativas”. Mana 16 (2): 471-499. https://revistas.unc.edu.ar/index.php/antropologia/article/view/9103

—. 2017. “'Esperando justicia’. Trauma psíquico, temporalidad y movilización política en la Argentina actual”. Papeles del CEIC. International Journal on Collective Identity 2017/1, papel 170. http://dx.doi.org/10.1387/pceic.16921 
-. 2020. "Antropología política de las emociones: las movilizaciones de víctimas en América Latina”. The Journal of Latin American and Caribbean Anthropology 25 (1): 123-144. https:// doi.org/10.1111/jlca.12446

Zenobi, Diego y Maximiliano Marentes. 2020. "Panorama sobre la producción social de las víctimas contemporáneas”. En Movilización de víctimas y demandas de justicia en la Argentina contemporánea, editado por María Victoria Pitia y Sebastián Pereyra, 67-100. Buenos Aires: Teseo. 